\title{
Platelet Rich Fibrin - A Saviour for Replanted Teeth - A Review
}

\author{
Sanjana Mall ${ }^{1}$, Rajmohan Shetty ${ }^{2}$, Amitha Hegde ${ }^{3}$, Kavita Rai ${ }^{4}$ \\ 12,3,4 Department of Paediatric and Preventive Dentistry, A. B. Shetty Memorial Institute of Dental \\ Sciences, Mangalore, Karnataka, India,
}

\section{ABSTRACT}

The periodontal ligament is a unique specialised connective tissue between the cementum covering the tooth root and the alveolar bone. It is believed that periodontal ligament cells are responsible for not only osteogenesis and osteoclasia of the alveolar bone but also for fibrogenesis and fibroplasia of the ligament itself, as well as cementogenesis and the presence of cementoblasts on the root surface. Injury to the periodontal ligament (PDL) and its compromised healing (external inflammatory resorption and replacement resorption) has been cited as one of the major reasons for the failure of transplantation and replantation procedures. The necessity of having a healthy PDL so that the tooth can re-attach and be retained in the socket determines the prognosis of replanted teeth.

Thus, the importance of maintaining the periodontal viability has led to an increased interest in the development of platelet concentrates, which have been considered as autologous biomaterials having the ability to potentiate healing, repair, and regenerate. PRF (platelet rich fibrin) is a living biomaterial derived from human blood containing fibrin, platelets, growth factors, leukocytes and stem cells entrapped in a fibrin-based scaffold / matrix, which has been documented to promote bone and soft tissue healing and regeneration. PRF technology has grabbed the attention of clinicians because it is readily available, is easy to prepare, can be produced immediately at the chairside, is easy to use, and widely applicable in dentistry, while being financially realistic for the patient and the clinician. Thus, the purpose of this review is to enumerate the biologic, chemical and physical properties of PRF and highlight the essential role it plays in periodontal regeneration and repair, which can be highly beneficial in improving the treatment success rate of transplantation and replantation procedures.

\section{KEY WORDS}

Platelet Rich Fibrin, Replantation, Transplantation, Periodontal Ligament, Periodontal Regeneration
Corresponding Author:

Dr. Kavita Rai,

Department of Paediatric Dentistry,

A. B. Shetty Memorial Institute of

Dental Sciences, Mangalore,

Karnataka, India.

E-mail: kavhegde@gmail.com

DOI: $10.14260 / j e m d s / 2021 / 574$

How to Cite This Article:

Mall S, Shettty R, Hegde A, et al. Platelet rich fibrin - a saviour for replanted teeth - a review. I Evolution Med Dent Sci 2021;10(33):2816-2823, $10.14260 / \mathrm{jemds} / 2021 / 574$

Submission 18-01-2021,

Peer Review 12-06-2021,

Acceptance 19-06-2021,

Published 16-08-2021.

Copyright (c) 2021 Sanjana Mall et al. This is an open access article distributed under Creative Commons Attribution License [Attribution 4.0 International (CC BY 4.0)] 


\section{BACKGROUND}

To prevent the loss of tooth and preserve the natural dentition, procedures such as transplantation and re-implantation of teeth have been used as treatment options for many years. ${ }^{1}$ Fleming $\mathrm{G}$ and Hoek and colleagues defined these terms under three broad categories ${ }^{2}$

- Replantation - The act of replanting a tooth with a vital or non-vital pulp in the same alveolar socket from which it had been removed, either surgically or as a result of trauma.

- Transplantation - The operation of transferring a tooth, one with a vital pulp or one with an obturated root canal, from one site to another in the same individual or from one individual to another.

- Autogenous tooth transplantation - Transplantation of teeth from one site to another in the same individual, involving transfer of embedded, impacted, or erupted teeth into extraction sites or into surgically prepared sockets.

The failure of the above mentioned procedures have been cited due to two main reasons frequently, i.e. external inflammatory resorption and replacement resorption (ankylosis) following injury to the periodontal ligament. ${ }^{3}$ The former is initiated when there is a combination of ingress of bacterial toxins with damage to the outer cemental surface and periodontal ligament while the latter occurs when injury occurs to more than $20 \%$ of the root surface leading to extensive damage of the innermost layer of the periodontal ligament.4,5 Scheff et al. (1890) elaborated on the role of periodontal ligament (PDL) and its role in the outcome of replantation procedures. The necessity of having a healthy PDL so that the tooth can re-attach and be retained in the socket were also conclusions drawn by the study of Hammer et al. ${ }^{6}$ Tronstad also stated that ankylosis is initiated when the PDL is damaged beyond repair and the exposed surface of the root gets covered by bone. ${ }^{7}$ Thus PDL is an integral part of the attachment apparatus which prevents the tooth root surface to come in contact with the alveolar bone.

Following loss of attachment from the socket, the periodontal ligament and the surface cementum of the tooth can undergo healing and repair only when the injured area covers less than $20 \%$ of the root surface. ${ }^{8}$ Loss of viable periodontal ligament cells and damage to the periodontal ligament after luxation type injuries (mechanical trauma incurred during extraction) mainly occurs from dehydration. ${ }^{9}$ Therefore, lower the extra alveolar dry time, increased is the likelihood of success of these procedures. Half-hour dry alveolar extra time has been established as the gold standard for the replantation. ${ }^{10}$ Jang et al. stated that an extra-oral dry time of $<15$ minutes showed more favourable results for replanted teeth than those having an increased dry time of $>$ 15 minutes. ${ }^{11}$ Hammarström et al. also found that an extra-oral dry time of 1 hour revealed extensive root resorption. ${ }^{12}$ However, the extra-oral dry time is often beyond the control of the operator especially in avulsion injuries, so it is vital for other techniques to be introduced that can promote the healing and regeneration of PDL fibres and enhance the proliferation of periodontal ligament cells.

Platelet concentrates are considered as autologous biomaterials which have the ability to potentiate healing, repair and regeneration and have been a source of research in the field of guided tissue regeneration for many years. Kingston et al. in the year 1986 was the first to demonstrate their healing capabilities following which, the use of platelets have undergone massive evolutionary changes which has now lead to the development of platelet derived biologic scaffolds that aid in periodontal regeneration and repair. ${ }^{13}$ The aim for any regenerative procedure is to restore the normal function and architecture of the damaged area. ${ }^{14}$ Kawase in 2015 stated that the synergistic interaction between the scaffold (fibrin matrix), platelets, growth factors, leukocytes, and stem cells were considered as the gold standard for in vivo tissue healing and regeneration. ${ }^{15}$ The role of the biologic scaffold is to maintain the mechanical integrity, supply growth factors, control cell growth and induce cell differentiation while maintaining an inflammatory and infection free environment. This makes its role pivotal in tissue repair and regeneration. ${ }^{16}$ (PRF) platelet rich fibrin is a living biomaterial derived from human blood. It is also considered as an optimized blood clot consisting of fibrin, platelets, growth factors, leukocytes and stem cells that are presented as autologous fibrin-based scaffold / matrix. Inchingolo et al. in 2010 claimed that PRF allows the interaction between the fibrin matrix and local tissue (bone and soft tissue) which leads to natural tissue regeneration and healing.

The conclusions drawn from a systematic review and meta-analysis stated that an improvement in alveolar ridge preservation and healing of the bony socket were seen after the use of PRF. ${ }^{17}$ Another meta-analysis found that the application of PRF in open flap debridement enhances soft and hard tissue healing. ${ }^{18}$ However, studies on the role of PRF in periodontal tissue healing in tooth replantation procedures have been limited. Thus, the purpose of this review is to enumerate the, biologic, chemical and physical properties of PRF and highlight the essential role it can play in periodontal regeneration and repair, which can be highly beneficial in improving the treatment success rate of transplantation and replantation procedures.

\section{PLATELET RICH FIBRIN (PRF)}

It is an autologous second-generation platelet concentrate generated from centrifugation of freshly collected patient's blood. Unlike its predecessors, this platelet concentrate does not require the use of additives such as anticoagulant, bovine thrombin or calcium chloride, since polymerisation of the fibrinogen occurs naturally during centrifuging. This novel method was first used for oral and maxillofacial surgery by Choukroun et al. in the year 2001.

\section{Constituents and Structural Organization of PRF}

Fibrin Matrix

The formation of the blood clot starts when the blood comes in contact with the walls of the test tube (1 - 2 mins) during centrifuging. This initial clot will have diffuse and unhurried polymerization of fibrinogen into fibrin because of the presence of physiologically available thrombin, in the absence of any activators. ${ }^{20}$ 


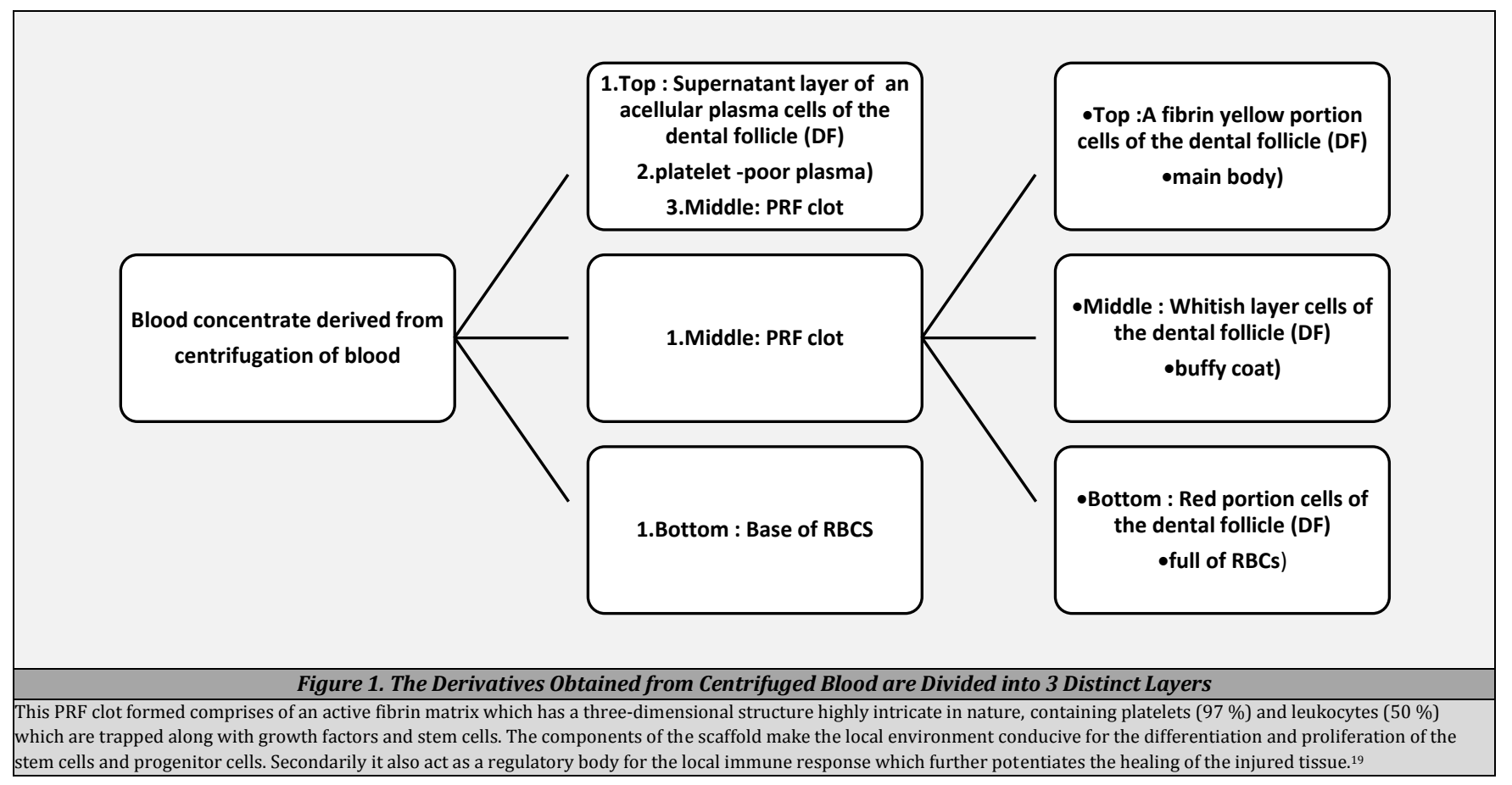

The three-dimensional fibrin network formed has equilateral junctions with low concentration of thrombin making the mesh finer, flexible and elastic. This favours cellular migration and cytokine entrapment. ${ }^{15}$ Additionally it also contains glycosaminoglycans (heparin and hyaluronic acid) which act as a chemoattractant towards the circulating peptides like platelets and cytokines. ${ }^{10}$

The components of the blood mainly platelets and the white blood cells within the fibrin meshwork secrete factors which promote growth and chemotactic proteins that induct epithelial, fibroblast, and endothelial cells to the healing site making PRF clot an "adhesive" scaffolding material. ${ }^{21}$

The low thrombin level in the clot is ideal for the migration of endothelial cells and fibroblasts making angiogenesis more favourable. Thus, the structure of the membrane mimics the extracellular matrix (ECM) as it improves and accelerates cell proliferation and differentiation, chemotaxis and angiogenesis hence playing a pivotal role in the stages of initial response in healing of injury. ${ }^{11}$

A study by Yajamanya et al. found that age could be an important factor which would dictate fibrin network patterns. With progressing age, there is a substantial reduction in the dense type of fibrin fibres and increase in the free arrangement of fibrin threads. ${ }^{22}$

\section{Platelets and Leucocytes}

Platelets are tiny colourless cellular fragments circulating in the blood, derived from the megakaryocytes having a life span of 8 - 10 days. The ability of the platelets to potentiate regeneration in tissues was introduced by Ross et al. in 1974 by elaborating its function in wound healing. The $\alpha$ - granules present in the thrombocytes are important reservoirs for growth factors. Upon contact with connective tissue following an injury these cells are "activated" to deliver these granules. Dynamic proteins are hence emitted which attach to the transmembrane receptors of the target cells leading to a cascade of reactions which cause the activation of intracellular signalling proteins.

The genomic expression of these proteins direct cellular proliferation, collagen synthesis and osteoid production. 10,14,15,21,23 The preparation of PRF by centrifuging leads to an instantaneous degranulation of the platelets and a substantial release of these factors. ${ }^{13}$ Platelets also initiate and modulate host immune response by assembling the defense cells of the body mainly leukocytes, lymphocytes, monocytes and endothelial cells which actively detect, capture and cause the lysis of pathogens. ${ }^{24}$

The rapid influx of neutrophils begin by release of inflammatory cytokines like interleukin-1 $\beta$ (IL - $1 \beta$ ), tumour necrosis factor- $\alpha$ (TNF - $\alpha$ ), and interferon- $\gamma($ IFN $-\gamma$ ) released from activated platelets. ${ }^{21}$ PRF has a high supplement of these leucocytes which shows superior antibacterial and osteoconductive activity. Osteoconduction of these cells primarily involve them acting as agents which facilitate the growth of bone. (T Alberktsson et al. 2001). They also participate in angiogenesis and lymphogenesis, thus making their actions synergistic with platelets. ${ }^{14}$

\section{Growth Factors}

The growth factors are a group of cytokine polypeptides having low molecular weight $(6-45 \mathrm{kDa})$ released by $\alpha$ granule. They have the property of inducing PDL cells proliferation on the exposed root surface and inhibit the action of osteoclasts enabling the possibility of PDL cell recovery and regeneration. ${ }^{25}$ In the study by Kornsuthisopon $\mathrm{C}$ et al. it was found that PRF upregulates the expression of transforming growth factor beta-1 (TGFB1), platelet derived growth factor subunit B (PDGFB), vascular endothelial growth factors A (VEGFA) which plays a vital role in healing of wounds while it downregulates the expression of pro-inflammatory cytokines - tumour necrosis factor alpha (TNFA) and interleukin 1 beta (IL1B) which reduces the inflammatory response. ${ }^{26}$ The role of the growth factors released in the PRF clot is tabulated below. (Table 


\begin{tabular}{|c|c|}
\hline Growth Factor & Function in PDL Regeneration \\
\hline $\begin{array}{l}\text { Platelet derived growth } \\
\text { factors (PDGFs) }\end{array}$ & $\begin{array}{l}\text { The periodontal tissues* of the oral cavity have receptors for } \\
\text { PDGFs. Their main action is to promote proliferation of } \\
\text { fibroblasts and osteoblasts and promote synthesis of } \\
\text { proteins. They also stimulate macrophages and neutrophils } \\
\text { and enhance } \\
\text { collagen synthesis \& collagenase secretion }\end{array}$ \\
\hline $\begin{array}{l}\text { Transforming growth } \\
\text { factor }-\beta \text { (TGF- } \beta \text { ), }\end{array}$ & $\begin{array}{l}\text { Induce to collagen I synthesis, fibronectin and fibroblast } \\
\text { proliferation. Additionally, they activate precursors of } \\
\text { osteoblasts and regulate the differentiation of cementoblasts } \\
\text { and contribute to the formation of bone matrix. They also } \\
\text { have an inductive action on endothelial cells which promote } \\
\text { angiogenesis }\end{array}$ \\
\hline $\begin{array}{l}\text { Vascular endothelial } \\
\text { growth factor (VEGF) }\end{array}$ & $\begin{array}{l}\text { Initiation of angiogenesis. } \\
\text { Promoting endothelial cell survival }\end{array}$ \\
\hline $\begin{array}{l}\text { Insulin-like growth } \\
\text { factor -1(IGF-1). }\end{array}$ & $\begin{array}{l}\text { Potent agents of cell protection. } \\
\text { Induce survival signals and prevent apoptosis. } \\
\text { Act as regulating bodies for cellular multiplication. } \\
\text { These properties are highly desirable when the PDL cell } \\
\text { viability is to be maintained during extra-alveolar dry time. }\end{array}$ \\
\hline $\begin{array}{l}\text { Epidermal growth } \\
\text { factor (EGF) }\end{array}$ & $\begin{array}{l}\text { Primarily target endothelial cells. } \\
\text { Promotes capillary proliferation and chemotaxis. } \\
\text { Induces multiplication of mesenchymal cells. }\end{array}$ \\
\hline \multicolumn{2}{|c|}{ Table 1. The Function of Growth Factors in PDL Regeneration } \\
\hline
\end{tabular}

Release of Growth Factors

The mechanical properties (tangled fibrous architecture) of PRF leads to a slow and controlled release of growth factors along with delayed release of platelets and cytokines in the circulation. In addition, the presence of glucose glycosaminoglycans cause a slow release of cytokines during the degradation of the PRF scaffold, thereby prolonging the action time of these factors. ${ }^{27}$ The release of these factors in PRF reaches its optimum peak at 14 days which coincides with the pattern of growth and remodelling of periapical tissues. ${ }^{28}$

In vitro studies evaluating the duration of release of growth factors in PRF have stated that a steady release is seen between a time period of $7-28$ days. Kobayashi et al. compared the effect of different preparation protocols on the release of growth factors having a time interval of 15 minutes, 1 hour, 1 day, 3 days and 10 days. He also confirmed that PRF contained more growth factors that were gradually released over time. ${ }^{29}$ Similar findings were reported by Su et al. who stated that application of PRF within the first 1 hour showed an initial burst of release which gradually became continuous and slow in the next 5 hours. ${ }^{30}$ In addition it has also been shown that the biodegradation of PRF in the tissue is faster and favourable to the host. ${ }^{31}$

\section{Preparation of PRF $\mathbf{1 3 , 1 9 , 2 0 , 2 1 , 2 3}$}

\section{Step 1. Blood Drawing}

The simple preparation protocol of PRF is a major advantage Blood is taken from the individual and transferred to the vacutainer just before or during the operative procedure and immediately processed in the centrifuge (within 2 minutes of collection of sample).

\section{Step 2. Centrifugation}

It is important to prevent any vibrations during the centrifuging process to obtain a stable clot. This is achieved by placing test tubes on the opposite side for balance.

\section{Clinical Implication}

It is important to not delay the centrifugation as the coagulation cascade gets activated as soon as the blood comes and touches the walls of the test tube. ${ }^{20}$

\section{Centrifugation Protocol for PRF Membrane}

Standard protocol (Choukron's ) ${ }^{31}$ - 3000 rpm / 10 minutes The clot obtained is viscous, thick with minimal spacing between the fibrin threads and has less cellularity.

Leukocyte and Platelet-Rich Fibrin ( $L$ - PRF) ${ }^{33}$ Speed $2700 \mathrm{rpm} / 12$ minutes - Larger clots and membranes having increased fibrin density and a more substantial release of growth factors. This thick fibrin matrix reduces the number of platelets in the fibrin mesh and causes an intense proliferation in the PRF in the first 24 hours, so the initial release of PDGF, VEGF and TGF- $\beta$ factors are high. It is also called as the Dohan Ehrenfest's protocol. This PRF membrane has been deemed apt as a biomaterial for socket preservation. ${ }^{34}$

\section{Advanced PRF (A-PRF) 35}

$1300 \mathrm{rpm} / 8$ minutes - enriched with leukocytes and higher concentration of growth factors. It has another variant called as the injectable PRF (i-PRF) which has a liquid consistency with similar properties.

\section{Clinical Implication}

In patients with blood disorders and who are on long term anti-coagulant therapy require a centrifuging time of greater length and even an increased waiting period for clot stabilization. ${ }^{20}$

\section{Distribution of PRF Constituent after Centrifugation}

Following the completion of the centrifugation protocol, the clot is allowed to rest / mature for approximately 4 - 8 minutes before extracting it from the tube. The force of centrifugation during PRF preparation leads to higher concentration of thrombin and fibrinogen at the RBC end of the PRF sample. The fibrin fibres concentrated here are of higher density and smaller diameter making them less porous.

The decreased porosity of the mesh traps platelets which induce a locking effect on the cytokines and thrombin. Secondarily the concentration of the cytokines in the PRF depends upon their molecular weight, large granules or molecules, such as platelets, PDGF-BB (31 kDa), and TGF-b1 (25 kDa) which are near the RBC end while lower molecular weight IGF-1 (7 $\mathrm{kDa})$ is principally circulating, tending to concentrate in the upper region of the test tube near the plasma end. ${ }^{35}$

Choukroun et al. in his study found that by reducing the relative centrifugation force, the aggregation of leukocytes and platelets at the bottom of the tube can be prevented. This would aid in the preparation of liquid injectable PRF (i- PRF) scaffolds having a uniform and rich concentration of platelets, leukocytes, and growth factors. This modification of PRF is easily admissible to the patient and with the added advantage of acting as a storehouse of growth factors. ${ }^{35}$ Thus, depending on their white blood cell concentration and fibrin design, PRF can be classified as - (Figure 2) ${ }^{15}$

\section{Clinical Implication}

As the region near the red thrombus is rich in platelets, that part of the clot should be placed close to the grafting / surgical site. ${ }^{21}$ 


\section{Molecular Action of PRF in Periodontal Regeneration}

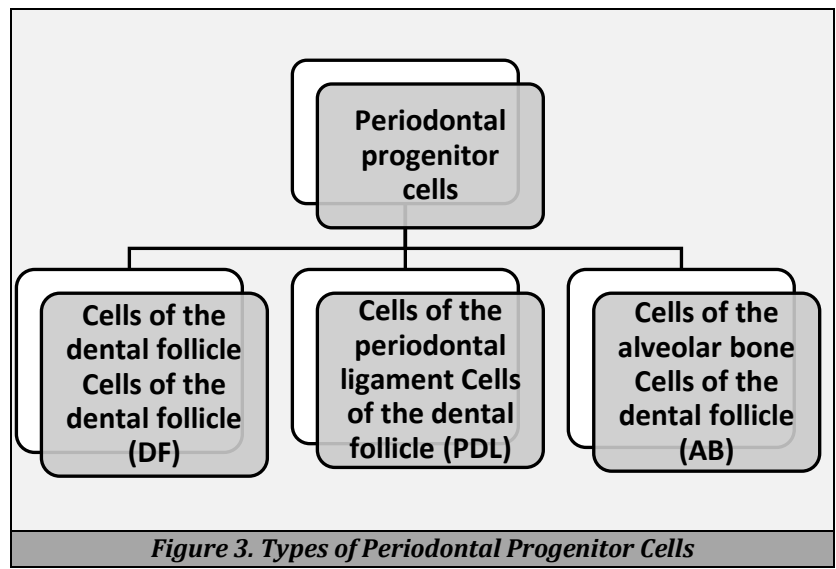

For regeneration of periodontal tissue, a biologic scaffold should have good biocompatibility and biodegradability where the degeneration of the material can be regulated. It should be easy to store, disinfect and extract and be osteoinductive and osteoconductive to facilitate cell adhesion and proliferation. In a study by Duan et al. PRF showed increased proliferation of hPDLCs (human periodontal ligament cells) in a dose dependant manner. ${ }^{27}$ This was considered as one of the most pivotal factors which would govern the regeneration of the periodontium. Metabolically active periodontal progenitor cells can be classified under three categories (Figure 3$)^{28}$

$Q$ li et al. in his study found that PRF had a stronger influence on $\mathrm{AB}$ and $\mathrm{DF}$ cells where proliferation occurred much earlier than PDL progenitors ${ }^{36}$ A positive proliferation and migration of gingival fibroblasts and periodontal ligament fibroblasts were seen with the application of both A-PRF and L-PRF, where L-PRF showed faster cell migration at the later stages of wound closure according to the study by Pitzurra et al. ${ }^{37}$ The extracellular signal-regulated protein kinase (ERK) signalling pathway is one of the mitogen-activated protein kinase cascades which helps in regulating cell growth and differentiation. Phosphorylation of ERK was enhanced by PRF in PDLFs, leading to an increase in their cellular proliferation. ${ }^{38}$

The expression of osteoprotegerin (OPG) which is a natural inhibitor of osteoclast differentiation is upregulated by PRF which causes an upregulation of the OPG protein expression of the osteoblast cell line and pulp cells. ${ }^{39}$ Awadeen et al. found in his animal study that PRF membranes exhibited faster granulation tissue formation leading to a newly formed osteoid tissue showing a more durable and effective differentiation and proliferation of rat osteoblasts. $\mathrm{He}$ concluded that bone healing also became highly favourable with the use of PRF, even in the long term. ${ }^{40}$

ALP (alkaline phosphatase) is a biomarker for osteogenic differentiation. Detection of high levels of ALP marks an increased presence of osteoblasts and bone deposition. ${ }^{36}$ PRF upregulates the activity of ALP which leads to the development of osteoblast-like features in human PDLFs suggesting their differentiation into osteoblasts. A strong (ALP) activity of PDLFs has potent effect on the apposition of acellular cementum. ${ }^{38}$
RUNX2 is a bone transcription factor which acts as an early transcriptional regulator in the process of osteogenic differentiation and also induces primary binding protein of TGF- $\beta 1$ which is a major growth factor in the PRF involved in the regulation of multi-lineage differentiation of cells. The expression of RUNX2 also gets upregulated by PRF treatment. 21

A systematic review which evaluated mesenchymal stem cell (MSC) periodontal regenerative potential in animal models showed that PDL-MSC promoted increased periodontal ligament (PDL) and cementum regeneration. ${ }^{41}$ Zhao et al. stated that the stem cells remaining in the alveolus were stimulated by the PRF to differentiate and form tissues similar to periodontal ligament. 42

Yang et al. in his histologic and histomorphometric study found that 4 weeks after PRF placement, tissues similar to the periodontal ligament and cementum were found. However, the thickness of PDL space was found to be irregular and the cementum deposition also had variable thickness on the resorbed dentin surface of the root. However, these irregularities were found to be resolved by 8 weeks. ${ }^{43}$ In another study by Duan et al. the formation of a thin layer of cellular cementum with PDL fibres perpendicular to the root surface and concomitant regeneration of supporting alveolar bone was established following PRF placement. ${ }^{27}$

Thus, PRF can promote the formation of both cementum and PDL fibres.

In addition, the leucocytes in the fibrin network reduce the local inflammation and enhance the host's ability to resist infection during the degradation process. Castro et al. detected antimicrobial activity of the L-PRF membrane against $P$. gingivalis. Hence the cumulative effects of the constituents of PRF enhance the guided tissue regeneration of the periodontal ligament. ${ }^{44}$

\section{Advantages of PRF 15,17,21,35,45,46}

- Natural (autologous) biomaterial

- Mode of preparation

- No anticoagulants are used

- Single spin centrifugation

- Structural Advantages

- Slow natural polymerization

- Highly pliable and elastic

- Increased concentration of intrinsic cytokines which can be modified according to the centrifugation speed.

- Acts as a regulatory body for the immune response and action

- Sustained release of growth factors over a long period of time

- Affordable and cost effective

- Risk of use in patients with systemic disorders is minimal

\section{Limitations of PRF 15,19,21,45,46}

- Short handling time

- $\quad$ Elasticity and faster biodegradability may restrict its use in guided tissue regeneration.

- Large amounts of the material cannot be prepared 
- $\quad$ Long term storage / refrigeration may alter the structural integrity and even cause bacterial contamination of the membrane

\section{Evidence of the Role of PRF in Replantation and Autotransplantation Procedures}

Navarro et al. found that after a dry extra-alveolar period of two hours, the expected adverse conditions of PDL cell viability can be reduced with the use of PRF. This could provide a more successful treatment outcome as seen in the immediate re-implantation. ${ }^{10}$

A qualitative analysis carried out by Bucchi et al. concluded that the use of platelet concentrates in replanted teeth promoted more effective periodontal repair, greater ligament regeneration and reduced ankylosis and inflammation. ${ }^{47}$

The use of PRF in the intentional replantation of endodontically failed molar by Deshpande et al. found a two year successful follow up with no signs of inflammatory or replacement resorption. ${ }^{10}$ In another case report by Rayana et al. replantation of a severely compromised periodontal tooth with PRF also showed no complications after a 12 month follow up. 48

Autogenous tooth transplantation of immature third molar using PRF to induce regeneration of the periodontal tissues and pulpal formation with sustainable and accelerated healing was undertaken by Alkofahi et al. and Devi et al.49,50

Both reported a continued root formation after 2 years of follow-up. In a similar case report of autotransplantation of ectopically erupted teeth by Chaudhary et al. and Kim et al. the use of PRF showed a successful treatment outcome after a follow up period of 1 year. ${ }^{31,51}$

\section{CONCLUSIONS}

Thus, guided tissue engineering by PRF has shown promising results; however, studies with long term follow up are needed. Cho SY et al. stated that immediate complications following replantation usually manifest within the initial $1^{\text {st }}$ year, however a follow up protocol of 3 years needs to be done to check for the occurrence of any late complications and also evaluate the long-term effect of PRF. ${ }^{8}$

The ability of the PDL cells to survive and recover and undergo proliferation and repair on the degenerated root surface of exarticulated teeth largely depends on the presence of a conducive local environment which can replenish its cellular nutrients and promote healing. PRF is an effective biomaterial which manifests these properties and can be considered as a "living tissue" preparation for natural guided tissue regeneration.

Although extensive studies have been carried out to understand the properties of PRF, further in vivo studies with long term follow up are needed to evaluate the PRF preparation which is best suited for replantation of teeth and periodontal regeneration.

Financial or other competing interests: None.

Disclosure forms provided by the authors are available with the ful text of this article at jemds.com.

\section{REFERENCES}

[1] Yu SJ, Le JS, Jung UW, et al. Effect of fibroblast growth factor on injured periodontal ligament and cementum after tooth replantation in dogs. Journal of Periodontal \& Implant Science 2015;45(3):111-9.

[2] Natiella JR, Armitage JE, Greene GW. The replantation and transplantation of teeth. Oral Surgery, Oral Medicine, Oral Pathology 1970;29(3):397-419.

[3] Finucane D, Kiniros MJ. External inflammatory and replacement resorption of luxated, and avulsed replanted permanent incisors: a review and case presentation. Dental Traumatology 2003;19(3):170-4.

[4] Tronstad L. Root resorption: etiology, terminology and clinical manifestations. Endod Dent Traumatol 1988;4(6):241-52.

[5] Finucane D, Kinirons MJ. External inflammatory and replacement resorption of luxated and avulsed replanted permanent incisors: a review and case presentation. Dental Traumatology 2003;19:170-4.

[6] Rouhani A, Javidi B, Habibi $M$, et al. Intentional replantation: a procedure as a last resort. J Contemp Dent Pract 2011;12(6):486-92.

[7] Singh P. Endo-perio dilemma: a brief review. Dent Res J (Isfahan) 2011;8(1):39-47.

[8] Rosa DCL, Simukawa ER, Capelloza ALA, et al. Alveol odental ankylosis: biological bases and diagnostic criteria. RGO Rev Gaúch Odontol 2019;67(6):e2019003.

[9] Hadi A, Marius C, Avi S, et al. Ankylosed permanent teeth: incidence, etiology and guidelines for clinical management. Med Dent Res 2018.

[10] Bortolini L, Barchiki F, Navarro W Jr, et al. Assessment of platelet-rich fibrin in the maintenance and recovery of cell viability of the periodontal ligament. Sci Rep 2019;9(1):19476.

[11] Becker BD. Intentional replantation techniques: a critical review. Journal of Endodontics 2018;44(1):1421.

[12] Deshpande NM, Shah D, Wadekar S. Maintenance of cell viability in extraoral conditions for a case of intentional replantation to retrieve a separated endodontic instrument. J Conserv Dent 2019;22(2):207-12.

[13] Saini K, Chopra P, Sheokand V. Journey of platelet concentrates: a review. Biomed Pharmacol J 2020;13(1):185-91.

[14] Giusti I, D'Ascenzo S, Macchiarelli G, et al. In vitro evidence supporting applications of platelet derivatives in regenerative medicine. Blood Transfus 2020;18(2):11729.

[15] Hartshorne J, Gluckman H. A comprehensive clinical review of Platelet Rich Fibrin (PRF) and its role in promoting tissue healing and regeneration in dentistry. Part 1: definition, development, biological characteristics and function. International Dentistry African Edition 2018;6(5):34-48.

[16] O'Brien FJ. Biomaterials \& scaffolds for tissue engineering. Material Today 2011;14(3):88-95.

[17] Pan J, Xu Q, Hou J, et al. Effect of platelet-rich fibrin on alveolar ridge preservation: A systematic review. J Am Dent Assoc 2019;150(9):766-78. 
[18] Li A, Yang H, Zhang J, et al. Additive effectiveness of autologous platelet-rich fibrin in the treatment of intrabony defects: A PRISMA-compliant meta-analysis. Med (Baltimore) 2019;98(11):e14759.

[19] Castro AB, Meschi N, Temmerman A, et al. Regenerative potential of leucocyte- and platelet-rich fibrin. Part A: intra-bony defects, furcation defects and periodontal plastic surgery. A systematic review and meta-analysis. J Clin Periodontol 2017;44(1):67-82.

[20] Hartshorne J, Gluckman H. A comprehensive clinical review of Platelet Rich Fibrin (PRF) and its role in promoting tissue healing and regeneration in dentistry. Part 2. International dentistry african edition 2018, 6(5): 34-48.

[21] Preeja C, Arun S. Platelet-rich fibrin: its role in periodontal regeneration. The Saudi Journal for Dental Research 2013. http://dx.doi.org/10.1016/j.ksujds.2013.09.001

[22] Yajamanya SR, Chatterjee A, Babu CN, et al. Fibrin network pattern changes of platelet-rich fibrin in young versus old age group of individuals: a cell block cytology study. J Indian Soc Periodontol 2016;20(2):151-6.

[23] Arunachalam M, Pulikkotil SJ, Sonia N. Platelet rich fibrin in periodontal regeneration. The Open Dentistry Journal 2016;10(Suppl 1):174-81.

[24] Ali RA, Wuescher LM, Worth RG. Platelets: essential components of the immune system. Curr Trends Immunol 2015;16:65-78.

[25] Azzaldeen A, Mai A, Muhamad AH. Platelet-rich fibrin (PRF) in dentistry. International Journal of Applied Dental Sciences 2019; 5(4):1-8.

[26] Kornsuthisopon C, Pirarat N, Osathanon T, et al. Autologous platelet-rich fibrin stimulates canine periodontal regeneration. Scientific Reports 2020;10:1850. https://doi.org/10.1038/s41598-02058732-x

[27] Duan X, Lin Z, Lin X, et al. Study of platelet-rich fibrin combined with rat periodontal ligament stem cells in periodontal tissue regeneration. J Cell Mol Med 2018;22(2):1047-55.

[28] Narang I, Mittal N, Mishra N. A comparative evaluation of the blood clot, platelet-rich plasma, and platelet-rich fibrin in regeneration of necrotic immature permanent teeth: a clinical study. Contemp Clin Dent 2015;6(1):63-8.

[29] Kobayashi E, Fluckiger L, Fujioka-Kabayashi M, et al. Comparative release of growth factors from PRP, PRF and advanced-PRF. Clin Ora l Invest 2016;20(9):2353-60.

[30] Su CY, Kuo YP, Tseng YH, et al. In vitro of grow factors released from platelet-rich fibrin (PRF): a proposal to optimize the clinical applications of FRP. Oral Surg Oral Med Oral Pathol Oral Radiol Endod 2009;108(1):56-61.

[43] Yang JM, Yang KI, Lee KH, et al. Effects of platelet-rich plasma on tooth replantation in dogs: a histologic and histomorphometric analysis. J Periodontal Implant Sci 2018;48(4):224-35.

[44] Castro AB, Herrero ER, Slomka V, et al. Antimicrobial capacity of leucocyte-and platelet rich fibrin against periodontal pathogens. Scientific Reports 2019;9:81-8. https://doi.org/10.1038/s41598-019-44755-6

[45] Kumar RV, Shubhashini N. Platelet rich fibrin: a new paradigm in periodontal regeneration. Cell Tissue Bank 2013;14(3):453-63.
[31] Chaudhary Z, Kumar YR, Mohanty S, et al. Amalgamation of allogenic bone graft, platelet-rich fibrin gel, and PRF membrane in auto-transplantation of an impacted central incisor. Contemp Clin Dent 2015;6(2):250-3.

[32] Ehrenfest DMD, Del Corso M, Diss A, et al. Threedimensional architecture and cell composition of a Choukroun's platelet-rich fibrin clot and membrane. J Periodontol 2010;81(4):546-55.

[33] Marchetti E, Mancini L, Bernardi S, et al. Evaluation of different autologous platelet concentrate biomaterials: morphological and biological comparisons and considerations. Materials 2020;13(10):2282.

[34] Bai MY, Wang CW, Wang JY, et al. Three-dimensional structure and cytokine distribution of platelet-rich fibrin. Clinics (Sao Paulo) 2017;72(2):116-24.

[35] Choukroun J, Ghanaati S. Reduction of relative centrifugation force within injectable platelet-rich-fibrin (PRF) concentrates advances patients' own inflammatory cells, platelets and growth factors: the first introduction to the low speed centrifugation concept. Eur J Trauma Emerg Surg 2018;44(1):87-95.

[36] Li Q, Pan S, Dangaria SJ, et al. Platelet-rich fibrin promotes periodontal regeneration and enhances alveolar bone augmentation. BioMed Research International 2013;2013:638043.

[37] Pitzurra L, Jansen IDC, de Vries TJ, et al. Effects of L-PRF and $\mathrm{A}-\mathrm{PRF}+$ on periodontal fibroblasts in in vitro wound healing experiments. J Periodont Res 2020;55(2):287-95.

[38] Chang YC, Zhao JH. Effects of platelet-rich fibrin on human periodontal ligament fibroblasts and application for periodontal infrabony defects. Australian Dental Journal 2011;56(4):365-71.

[39] Strauss FJ, Nasirzade J, Kargarpoor Z, et al. Effect of platelet-rich fibrin on cell proliferation, migration, differentiation, inflammation and osteoclastogenesis: a systematic review of in vitro studies. Clin Oral Investig 2020;24(2):569-84.

[40] Awadeen MA, Al-Belasy FA, Ameen LE, et al. Early therapeutic effect of platelet-rich fibrin combined with allogeneic bone marrow-derived stem cells on rats' critical-sized mandibular defects. World J Stem Cells 2020;12(1):55-69.

[41] Tassi SA, Sergio NZ, Misawa MYO, et al. Efficacy of stem cells on periodontal regen- eration: systematic review of pre-clinical studies. J Periodontal Res 2017;52(5):793812.

[42] Zhao YH, Zhang M, Liu NX, et al. The combined use of cell sheet fragments of periodontal ligament stem cells and platelet-rich fibrin granules for avulsed tooth reimplantation. Biomaterials 2013;34(22):5506-20.

[46] Mohan SP, Jaishangar N, Devy S, et al. Platelet-rich plasma and platelet-rich fibrin in periodontal regeneration: a review. J Pharm Bioallied Sci 2019;11(Suppl 2):S126-S30.

[47] Bucchi C, Arias A, Fuentes R. Platelet concentrates in the replantation of avulsed teeth: a systematic review. Int J Clin Exp Med 2016;9(12):22985-92.

[48] Rayana HK, Srinath R, Prakash S. Surgical re-entry of an intentionally replanted periodontally compromised tooth treated with Platelet Rich Fibrin (PRF): hopeless to hopeful. Journal of Clinical and Diagnostic Research 2016;10(6):ZD01-ZD04. 
[49] Alkofahi H, Maghaireh A, Fnaish M, et al. Application of platelet-rich fibrin as regeneration assistant in immediate auototransplantation of third molar with unformed roots: case report and review of literature. Article ID 8170646, Case Reports in Dentistry 2020;(11):1-6.

[50] Devi TP, Singh WS, Sanjeeta N, et al. Immediate autotransplantation of immature third molar with regeneration of recipient site using autologous plateletrich fibrin. Journal of Medical Society 2014;28(3):196-9.

[51] Lim Y, Kim J, Choi N, et al. Autotransplantation of ectopically impacted teeth: two case reports. J Korean Acad Pediatr Dent 2017;44(1):108-15. 